\title{
Symmetry on a Class of Multiparameter Markov Processes
}

Nie Dalu ${ }^{1}$, Xaoqin $\mathrm{Li}^{2}$, and Xie Yuquan ${ }^{3}$

${ }^{1}$ Guangdong University of Science and Technology, Dongguang, Guangdong, 523083, China

${ }^{2}$ Guangdong University of Science and Technology, Dongguang, Guangdong, 523083, China ${ }^{3}$ probability and satistics

September 30, 2021

\begin{abstract}
In this paper, we study the symmetry on a class of multiparameter Markov Processes in Khoshnevisan (2002), and obtain some important and interesting results.
\end{abstract}

\section{Hosted file}

Symmetry on a Class of Multiparameter Markov Processes.pdf available at https://authorea.com/ users/438731/articles/539833-symmetry-on-a-class-of-multiparameter-markov-processes 